\title{
Egg parasitoids of Arboridia apicalis (Nawa, 19/3) (Hemiptera, Cicadellidae), a leafhopper pest of grapevines in Japan, with description of a new species of Anagrus Haliday, 1833 (Hymenoptera, Mymaridae)
}

\author{
Serguei V. Triapitsyn', Tetsuya Adachi-Hagimori², Paul F. Rugman-Jones', \\ Natsuko Kado ${ }^{3}$, Nobuo Sawamura ${ }^{3}$, Yutaka Narai ${ }^{3}$
}

I Department of Entomology, University of California, Riverside, California, USA 2 Organization for Promotion of Tenure Track, University of Miyazaki, Miyazaki, Japan 3 Shimane Agricultural Technology Center, Izumo, Shimane, Japan

Corresponding author: Tetsuya Adachi-Hagimori (tadachi@cc.miyazaki-u.ac.jp)

Academic editor: Andreas Köhler | Received 9 March 2020 | Accepted 4 May 2020 | Published 3 July 2020

http://zoobank.org/04BAF072-83CE-4630-B101-4356A1688F77

Citation: Triapitsyn SV, Adachi-Hagimori T, Rugman-Jones PF, Kado N, Sawamura N, Narai Y (2020) Egg parasitoids of Arboridia apicalis (Nawa, 1913) (Hemiptera, Cicadellidae), a leafhopper pest of grapevines in Japan, with description of a new species of Anagrus Haliday, 1833 (Hymenoptera, Mymaridae). ZooKeys 945: 129-152. https:// doi.org/10.3897/zookeys.945.51865

\begin{abstract}
Several species of egg parasitoids (Hymenoptera: Mymaridae and Trichogrammatidae) of the leafhopper pest of grapevines in Japan, Arboridia (Arboridia) apicalis (Nawa) (Hemiptera, Cicadellidae), were reared and identified for the first time. Using a combination of genetic and morphological evidence, Anagrus (Anagrus) arboridiae Triapitsyn \& Adachi-Hagimori, sp. nov. (Mymaridae) is described and illustrated from Honshu Island (Shimane Prefecture) and Kyushu Island (Miyazaki Prefecture). It is shown to be different from Anagrus (Anagrus) japonicus Sahad and A. flaviapex Chiappini \& Lin, to which it is most similar; the latter species was originally described from China and is newly recorded here from Okinawa Island, Japan. Mitochondrial and nuclear ribosomal DNA sequence data provide clear evidence for the separation of A. arboridiae from A. flaviapex, A. japonicus, and some other members of the Anagrus (Anagrus) atomus (L.) species group. Two other species of Anagrus Haliday, A. (Anagrus) avalae Soyka and A. atomus, are also identified in Japan from eggs of the leafhoppers Edwardsiana ishidae (Matsumura) and Eurhadina ?betularia Anufriev, respectively. An updated key to females of the Japanese species of Anagrus
\end{abstract}

Copyright SergueiV.Triapitsyn et al. This is an open access article distributed under the terms of the Creative Commons Attribution License (CC BY 4.0), which permits unrestricted use, distribution, and reproduction in any medium, provided the original author and source are credited. 
is given. Oligosita pallida Kryger (a new record for Japan), Oligosita sp., and an Aphelinoidea (Aphelinoidea) sp. (Trichogrammatidae) were the other, although much less abundant, apparent egg parasitoids of $A$. apicalis in Shimane Prefecture, mainly in non-organic vineyards.

\section{Keywords}

Aphelinoidea sp., egg parasitoid, grapevine pest, identification key, natural enemy, Oligosita spp., taxonomy

\section{Introduction}

The leafhoppers Arboridia (Arboridia) apicalis (Nawa) (Fig. 1a) and A. (Arboridia) suzukii (Matsumura) (Hemiptera, Cicadellidae) have been recorded in Japan as pests of cultivated grapes, Vitis spp. (Vitaceae) (Tanaka et al. 1986; Sakagami 2003; Yamada 2003). Feeding by the leafhopper adults and nymphs causes stippling, a characteristic damage to the grape leaves (Fig. 1b-f); also, when abundant, particularly in the organic vineyards on Honshu Island, adult $A$. apicalis are a significant nuisance to the pickers at harvest by getting into peoples' faces. Both A. apicalis and A. suzukii are native to the Eastern Palaearctic and Northeastern Oriental regions, with more or less similar distributions: that of $A$. apicalis includes Japan (throughout), Korean Peninsula, Far East of Russia, mainland China and Taiwan (Guglielmino et al. 2012; Song and Li 2013, 2015; Oh et al. 2015; Dmitriev 2019) while A. suzukii occurs in Japan (Honshu, Kyushu, and Shikoku Islands), Korean Peninsula, Far East of Russia, mainland China, and Taiwan (Oh et al. 2015; Dmitriev 2019). Arboridia apicalis is a polyphagous leafhopper feeding on various deciduous trees and vines, such as cherry, grape, hawthorn, apple, pear, peach, mulberry, maple (Yamada 2003; Guglielmino et al. 2012; Song and Li 2015; Dmitriev 2019). The known host plants of A. suzukii, besides grape, are apple, pear, Manchurian cherry (Dmitriev 2019), and also Japanese chestnut; this leafhopper is a pest in the Japanese vineyards mainly in Kyushu Island, causing damage particularly to leaf edges whereas A. apicalis damages the entire leaf more uniformly (Yamada 2003, illustrated by Sakagami (2003)). Both species overwinter as adults in dropped leaves, weeds, cracks in bark, and under cover of buildings. On Honshu Island, A. apicalis has three generations per year, although, in greenhouses, it develops earlier and can have four generations per year (Yamada 2003).

Egg parasitoids of Arboridia spp. have been unknown in Japan, yet elsewhere several species of Mymaridae and Trichogrammatidae (Hymenoptera: Chalcidoidea) were reported from eggs of other species of this genus (Noyes 2019). In particular, Anagrus (Anagrus) turpanicus Triapitsyn \& Hu was described recently from eggs of the invasive leafhopper pest of grapes in Xinjiang Uyghur Autonomous Region of China, Arboridia kakogawana (Matsumura) (Hu and Triapitsyn 2016). Interestingly, A. kakogawana is native to Japan but it has not been reported there as a pest of cultivated grapes. One of the possible explanations for that, requiring further investigation, could be a possibility that the holotype female of $A$. kakogawana, collected (without indication of a host plant association) in Kakogawa (near Akashi), Hyogo Prefecture, Honshu Island (Mat- 


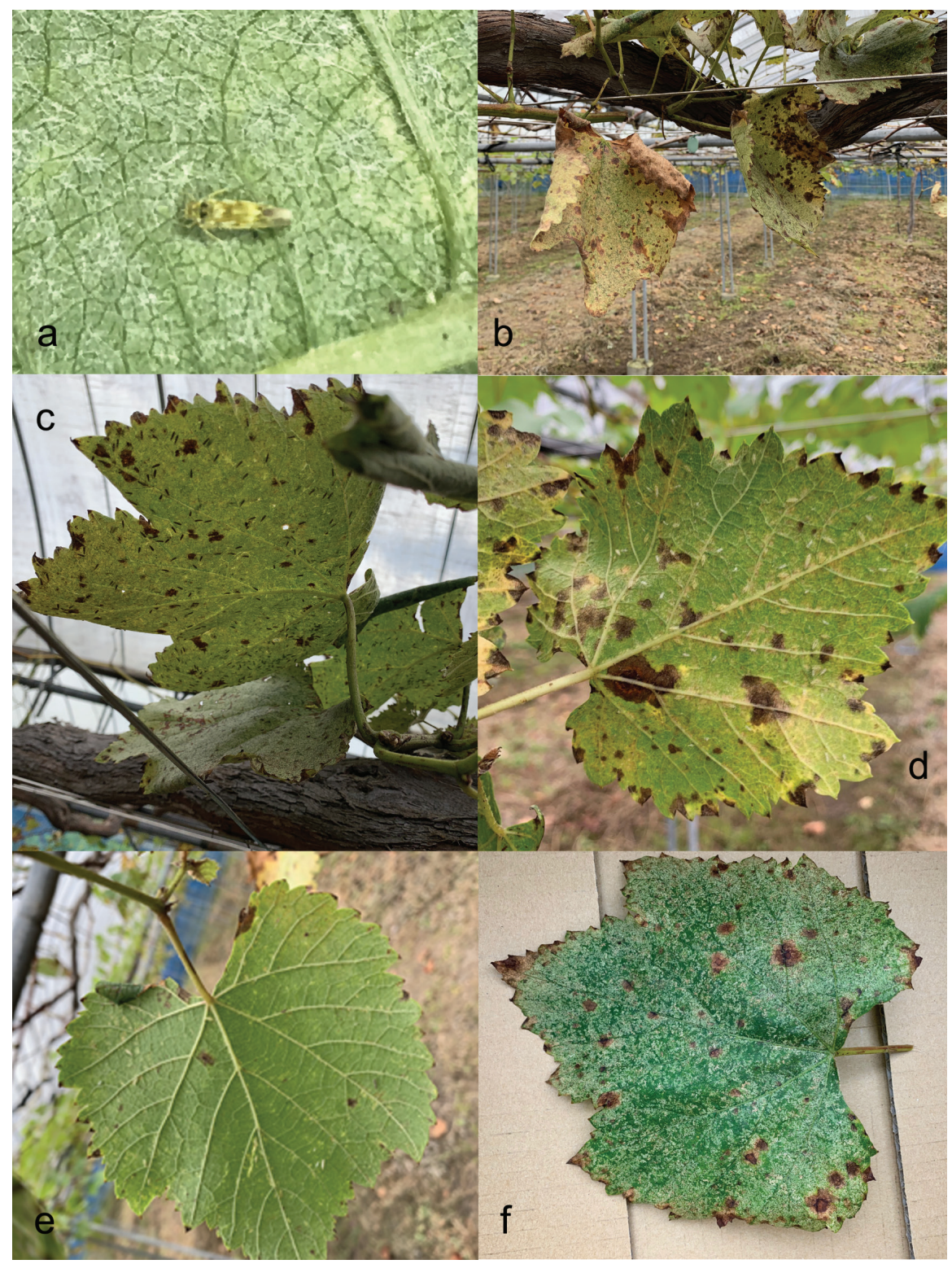

Figure I. Arboridia (Arboridia) apicalis and its damage to cultivated grapevines in Japan a adult (Takayama, Gifu Prefecture, Honshu Island) b heavy damage to grape leaves in a covered vineyard (Shimane Prefecture, Honshu Island, also c-f) $\mathbf{c}$ numerous adults on the underside of a grape leaf $\mathbf{d}$ nymphs on the underside of a grape leaf $\mathbf{e}$ light damage to a grape leaf by a few nymphs $\mathbf{f}$ heavy damage to a grape leaf.

sumura 1932), might not be conspecific with the males from Korea, on whose genitalic characters the current recognition of this species is based upon (Dworakowska 1970). According to our observations, eggs of $A$. apicalis are laid singly, embedded in the soft 
tissues of grapevines, such as leaf veins. In the commercial vineyards of Japan, many of which are covered from at least above to control temperature and humidity, grape leafhoppers are usually controlled by insecticides (e.g., Arai and Toyama 2018) so finding organic vineyards, which are not common, was essential to the success of this survey. Because, according to the personal observations of the first author in other countries, grape leafhoppers from several genera, including $A$. kakogawana, prefer to feed on the leaves inside the vines, where it is more shady, it appears that the practice of covering the vines in many Japanese vineyards (and thus providing favorable shady conditions) might enhance damage to the entire vine, including peripheral foliage.

As the first step towards the establishment of a biological control-based integrated pest management (IPM) of these grape leafhoppers in Japan, we identified egg parasitoids of $A$. apicalis collected mainly from organic vineyards.

\section{Materials and methods}

\section{Specimen collection}

Both adults and nymphs of $A$. apicalis were collected in Japan by sweeping from the grapevines at several vineyards in Shimane Prefecture, Honshu Island, as well as from the organic vineyard in Aya, Miyazaki Prefecture, Kyushu Island $\left(26^{\circ} 06^{\prime} 38^{\prime \prime N}\right.$, $129^{\circ} 41^{\prime} 16^{\prime \prime E}, 52 \mathrm{~m}$ ). Arboridia suzukii was not present in these sites. Parasitized eggs, which turn dark orange as the parasitoid larva develops and then pupates, were documented by dissections in Petri dishes of the heavily leafhopper-infested grape leaves from the organic Oku-Izumo vineyard (Black Olympia cultivar) in Unnan, Shimane Prefecture. In early October 2019, leaves and vines infested with A. apicalis were collected from one organic and two non-organic vineyards in Shimane Prefecture and also in the above-mentioned organic vineyard in Miyazaki Prefecture; these were placed in tightly taped carton boxes. To collect adult parasitoids and host leafhoppers (both adults and nymphs), two clear glass vials were inserted through the holes into each of the boxes, one on the top and the other on the side near the top of the box, the latter to maximize exposure to daylight coming through the window. The vials were also exposed to a constant light source in the laboratory, and the emerging individuals were collected in $80 \%$ ethanol at least once almost daily (except for some weekends) for at least 30 days. Both host leafhoppers and parasitoids were sorted to morphospecies and identified by the first author at the second author's laboratory at the University of Miyazaki Kibana Campus, Miyazaki City. The parasitoids were stored at $-20^{\circ} \mathrm{C}$ until they were shipped to the first author's laboratory at the Entomology Research Museum, University of California at Riverside, California, USA (UCRC). These specimens were used both for molecular analyses and taxonomic studies (as type material of the new species of Anagrus Haliday described below).

Voucher specimens of the grape leafhoppers resulting from this study are deposited in the insect collections of the Entomological Laboratory, Faculty of Agriculture, Ky- 
ushu University, Fukuoka, Japan (ELKU), Illinois Natural History Survey, University of Illinois at Urbana-Champaign, Champaign, Illinois, USA (INHS) and the UCRC. Their identities were confirmed by Dmitry A. Dmitriev (INHS).

\section{Taxonomic studies}

Morphological identifications of the Anagrus sp., made by the first author, were based mainly on females because males of many species of Anagrus are often similar and difficult to determine beyond a species group.

For the taxonomic description of the new species, the morphological terms of Gibson (1997), with some modifications made by Triapitsyn (2015), were used. All measurements (as length or length and width for the wings) are given in micrometers $(\mu \mathrm{m})$. Abbreviations used in the description and key are:

F funicle segment of the female antenna or flagellomere of the male antenna;

mps multi-porous plate sensillum or sensilla on the antennal flagellar segments (= longitudinal sensillum or sensilla, or sensory ridge(s)).

Specimens from ethanol were dried using a critical point drier, then point-mounted and labeled. Selected specimens were dissected and slide-mounted in Canada balsam. Slide mounts were examined under a Zeiss Axioskop 2 plus compound microscope (Carl Zeiss Microscopy, LLC, Thornwood, New York, USA) and photographed using the Auto-Montage system (Syncroscopy, Princeton, New Jersey, USA). Photographs were retouched where necessary using Adobe Photoshop (Adobe Systems, Inc., San Jose, California, USA).

Specimens of the parasitoids examined are deposited in the collections with the following acronyms:

CNC Canadian National Collection of Insects, Arachnids and Nematodes, Ottawa, Ontario, Canada;

ELKU Entomological Laboratory, Faculty of Agriculture, Kyushu University, Fukuoka, Japan;

UCRC Entomology Research Museum, Department of Entomology, University of California, Riverside, California, USA.

\section{DNA extraction, amplification, and sequencing}

DNA was extracted from two individual female wasps of the new species described herein using the "HotSHOT" method of Truett et al. (2000), in a total volume of $80 \mu \mathrm{L}$. This non-destructive method allowed for the recovery and slide-mounting of each specimen following extraction; each slide was then labeled with the assigned P. F. Rugman-Jones' primary molecular voucher PR number and UCRC database UCRC ENT number. The polymerase chain reaction (PCR) was employed to amplify 
the "barcoding" region of the mitochondrial cytochrome c oxidase subunit I gene (COI) and the internal transcribed spacer 2 (ITS2) region of nuclear ribosomal RNA (rRNA). Amplification and sequencing of the COI were performed using the same protocols as described in Triapitsyn et al. $(2018,2019 \mathrm{a}$, b) for some other species of Anagrus. It was only possible to sequence the ITS2 after cloning the amplicon as described in Triapitsyn et al. (2019b). For each specimen, two insert-positive clones were subsequently sequenced.

In addition to the specimens of the newly described species, the same methods were used to extract, amplify, and sequence the DNA from two individual females of Anagrus (Anagrus) japonicus Sahad, which represent the voucher specimens of the study by Adachi-Hagimori et al. (unpublished) (P. F. Rugman-Jones' molecular vouchers PR19-501 [UCRC_ENT 005517343] and PR19-502 [UCRC_ENT 005517344]), and also from one female of $A$. (Anagrus) flaviapex Chiappini \& Lin (data given below under "Comments"). Both species belong to the atomus species group of the nominate subgenus of Anagrus; all three specimens were recently collected in Okinawa Island, Ryukyu Islands, Japan.

All sequences generated in this study were deposited in GenBank (Benson et al. 2008).

\section{Genetic analysis}

The COI sequences generated from the five specimens in this study (GenBank accessions MT396446-MT396450) were combined with 45 others retrieved from GenBank, each of which was a unique haplotype identified in three earlier studies of members of the Anagrus 'atomus' species complex, which is altogether comprised of six nominal species (Zanolli et al. 2016 [34 haplotypes, KM677212-KM677245]; Nugnes et al. 2017 [11 haplotypes from KX691520-KX691551]). One further sequence, from A. (Anagrus) incarnatus Haliday [MK024811], a member of the incarnatus species group, was also retrieved for use as an outgroup, and the combined sequence data were subsequently aligned using MAFFT version 7.050 (Katoh and Standley 2013) and the Q-INS-i algorithm with default settings. This resulted in an aligned COI dataset containing 51 terminal taxa and 587 nucleotide positions. The only gaps in the matrix were the result of 147 missing bases at the 5' end of many of the sequences retrieved from GenBank. Genetic variation among our sequences was estimated by calculating uncorrected p-distances between all possible sequence pairs, using MEGA version 6 (Tamura et al. 2013). Gapped positions (i.e. at the 5' end) were removed for each sequence pair in the analysis. A neighbor-joining $(\mathrm{NJ})$ tree based on those p-distances was subsequently constructed, again using MEGA. Branch support was estimated using a bootstrap procedure with 1000 replicates.

Since phylogenetic inference from ITS2 is typically problematic due to large interspecific differences that make alignment of this region difficult and somewhat ambiguous, ITS2 sequences were examined "by eye" to corroborate the differentiation of our specimens based on COI. Furthermore, BLAST searches of the NCBI database were performed to assess their similarity to other members of the 'atomus' species complex. 


\section{Results}

\section{Taxonomy}

Mymaridae

\section{Anagrus (Anagrus) arboridiae Triapitsyn \& Adachi-Hagimori, sp. nov. http://zoobank.org/915C3341-6BD3-4E69-A6FD-8B47FD77792E}

Figures $2-4$

Type material. Holotype + (Fig. 3a, b, d), deposited in ELKU, on slide (Fig. 3c) labeled: 1. "Japan: Honshu Island Shimane Prefecture, Unnan Oku-Izumo vineyard, $35^{\circ} 17^{\prime} 20 " \mathrm{~N}, 132^{\circ} 55^{\prime} 46^{\prime \prime} \mathrm{E}, 155 \mathrm{~m}$ (organic Black Olympia table grapes heavily infested with Arboridia apicalis (Nawa) in a covered vineyard), leaves collected 4.x.2019, N. Kado, N. Sawamura, T. Adachi-Hagimori, S. V. Triapitsyn Emerged 6.x.2019, S. V. Triapitsyn"; 2. [magenta] "Anagrus (Anagrus) arboridiae Triapitsyn \& Adachi-Hagimori HOLOTYPE $\% ” ; 3$. "Det. by S. V. Triapitsyn 2019”; 4. [barcode database label/ unique identifier] "UCRC [bold] UCRC_ENT 005517345".

Paratypes. Japan: Honshu Island, Shimane Prefecture, Unnan, Oku-Izumo vineyard, $35^{\circ} 17^{\prime} 20^{\prime \prime} \mathrm{N}, 132^{\circ} 55^{\prime} 46^{\prime \prime} \mathrm{E}, 155 \mathrm{~m}$ (organic Black Olympia table grapes heavily infested with $A$. apicalis in a covered vineyard), collected 4.x.2019, N. Kado, N. Sawamura, T. Adachi-Hagimori, S. V. Triapitsyn, emerged from grape leaves: 5.x.2019, S.

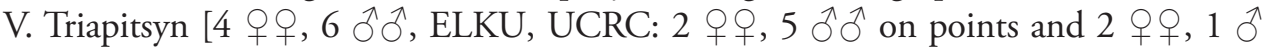
on slides (including 19 on slide, P. F. Rugman-Jones' molecular voucher PR19-504,

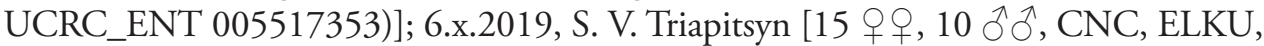

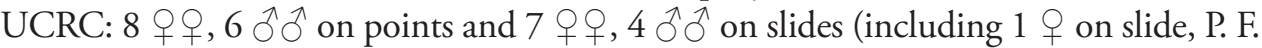
Rugman-Jones' molecular voucher PR19-503, UCRC_ENT 005517352)]. Kyushu Island, Miyazaki Prefecture, Higashimorokata, Aya, Kitamata, 32 $00^{\prime} 32^{\prime \prime N}, 131^{\circ} 14^{\prime} 26^{\prime \prime E}$, $86 \mathrm{~m}$ (Katsuki Wines LLC organic vineyard, Chardonnay wine grapes lightly infested with $A$. apicalis in a covered vineyard), leaves collected 30.x.2019, T. Adachi-Hagimori, S. V. Triapitsyn, emerged 6.xi.2019, S. V. Triapitsyn [1,+ 1 o on slides, UCRC].

Other (non-type) material examined. JaPAN: Honshu Island, Shimane Prefec-

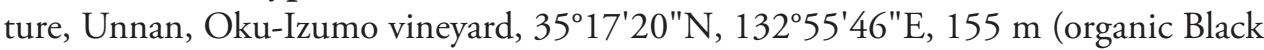
Olympia table grapes heavily infested with $A$. apicalis in a covered vineyard), collected 4.x.2019, N. Kado, N. Sawamura, T. Adachi-Hagimori, S. V. Triapitsyn: sweeping on

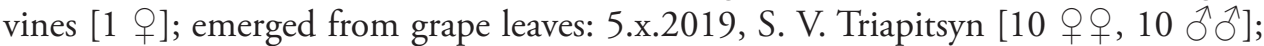

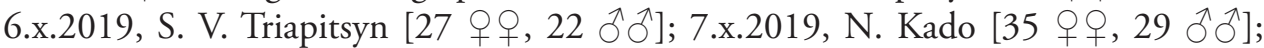

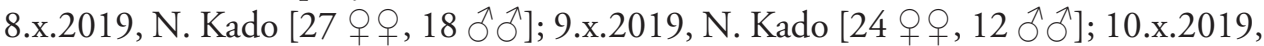

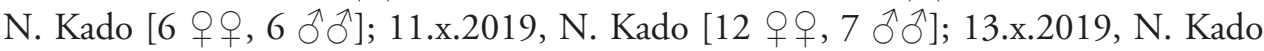

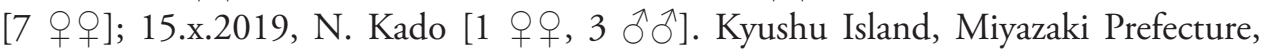
Higashimorokata, Aya, Kitamata, 3200'32"N, 13114'26"E, 86 m (Katsuki Wines LLC organic vineyard, Chardonnay wine grapes lightly infested with $A$. apicalis in a covered vineyard), leaves collected 30.x.2019, T. Adachi-Hagimori, S. V. Triapitsyn: emerged 31.x.2019, S. V. Triapitsyn [1 §]; emerged 2.xi.2019, T. Adachi-Hagimori 
a

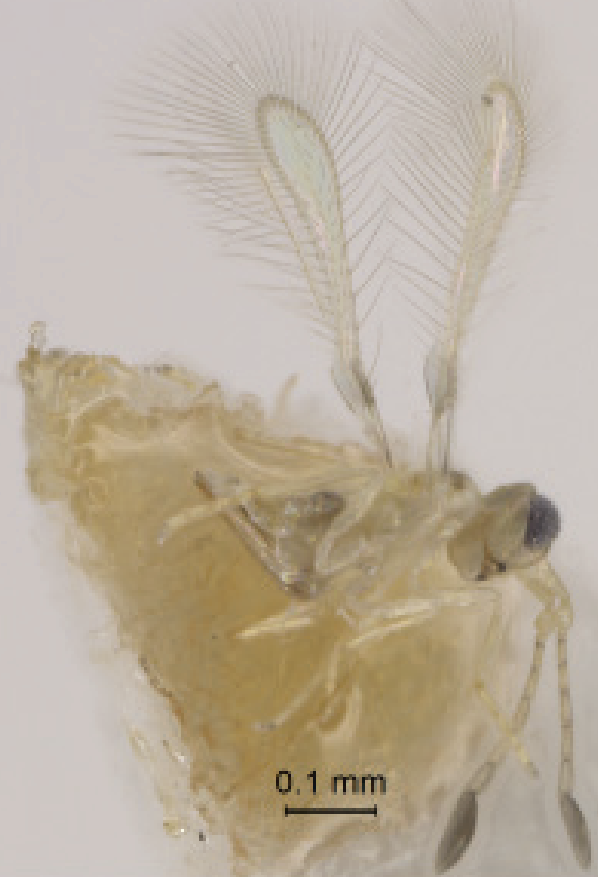

b

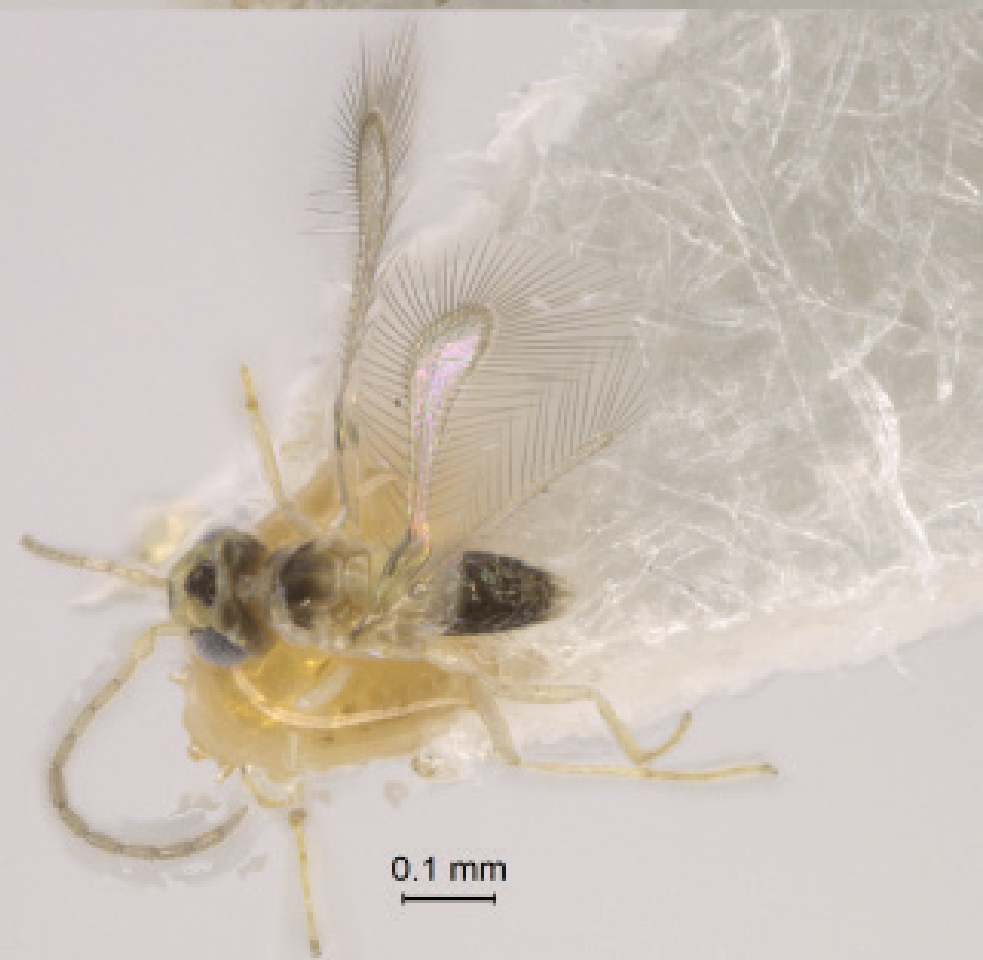

Figure 2. Anagrus arboridiae sp. nov. (paratypes from Unnan, Shimane Prefecture, Honshu Island, Japan) $\mathbf{a}$ habitus of female (lateral view) $\mathbf{b}$ habitus of male (dorsal view). 
[1 §]; emerged 4.xi.2019, T. Adachi-Hagimori [2 $q$ ?]; emerged 2.xi.2019, T. AdachiHagimori [ 1 ○]; emerged 5.xi.2019, S. V. Triapitsyn [1 9 ]. All in $80 \%$ ethanol in a freezer [UCRC].

Diagnosis. The new species is a member of the atomus species group of Anagrus (Anagrus) as defined by Chiappini et al. (1996). Female antenna (Fig. 3a) with mps on F3 (1), F4 (1), F5 (1 or 2), F6 (2), and clava (3); midlobe of mesoscutum without adnotaular setae; fore wing disc with a distinct subapical bare area (Figs 3b, 4b); ovipositor (Fig. 3d) 2.3-2.5× length of protibia. Male genitalia (Fig. 4c) with hooked digiti.

Morphologically, $A$. arboridiae is most similar to A. flaviapex, to which its female specimens with a more or less distinct bare area on the fore wing disc key in Triapitsyn (2015) and Li et al. (2018). Both taxa have one mps on F3 of the female antenna (Chiappini and Lin 1998). However, male genitalia of A. flaviapex have cone-shaped, straight digiti (Triapitsyn 1999) and body of the female is mostly brown (Triapitsyn 2015). Besides $A$. arboridiae, the three other known species within the nominate subgenus of Anagrus with hooked digiti of male genitalia and three mps on the clava of female antenna, the European A. vilis Donev and the Afrotropical A. scassellatii Paoli and $A$. sensillatus Viggiani \& Jesu (Chiappini and Mazzoni 2000), were assigned to the atomus species group by them and also by Triapitsyn (2015). More recently, Nugnes et al. (2017) placed these, without providing much of a justification and based solely on the hooked shape of the digiti of male genitalia, in a separate vilis species group of Anagrus (Anagrus). However, based on other morphological features of both sexes A. arboridiae is not related to $A$. vilis and either of them are not related to the two aforementioned Afrotropical species. Moreover, in males of $A$. japonicus from Okinawa Island, shape of the digiti is of an intermediate state between the strongly hooked (such as in A. arboridiae and A. vilis) and the straight ones (like in most other species within the atomus species group): these are more or less cone-shaped in dorsoventral view but notably curved in lateral view (Adachi-Hagimori et al. unpublished). Because the hooked shape of the digiti is likely to have evolved independently in the different lineages within the atomus species group sensu lato, we agree with the conclusion made by Chiappini and Mazzoni (2000) that by itself this feature should not be used for defining separate species groups without support of any additional characters. Thus, we do not recognize the vilis species group proposed by Nugnes et al. (2017) as a separate entity from the atomus species group.

Females of $A$. arboridiae are also similar to those $A$. japonicus that sometimes have an mps on F3, but the former always have distinct light brown and brown patches on the mesoscutum and the basal gastral terga respectively, which the latter species lacks.

An updated key to females of the Japanese species of Anagrus is provided below, as the latest key by Triapitsyn et al. (2019a) is already outdated after the addition of four species herein which are new to the fauna of Japan.

Description. Female (holotype and paratypes). Body length of dry-mounted, critical point-dried paratypes $400-500 \mu \mathrm{m}$, and of the slide-mounted paratypes 415$520 \mu \mathrm{m}$. Body (Fig. 2a) and appendages mostly pale yellow except funicle, occiput and almost all of mesoscutum (except posteriorly) light brown, transverse trabecula and 

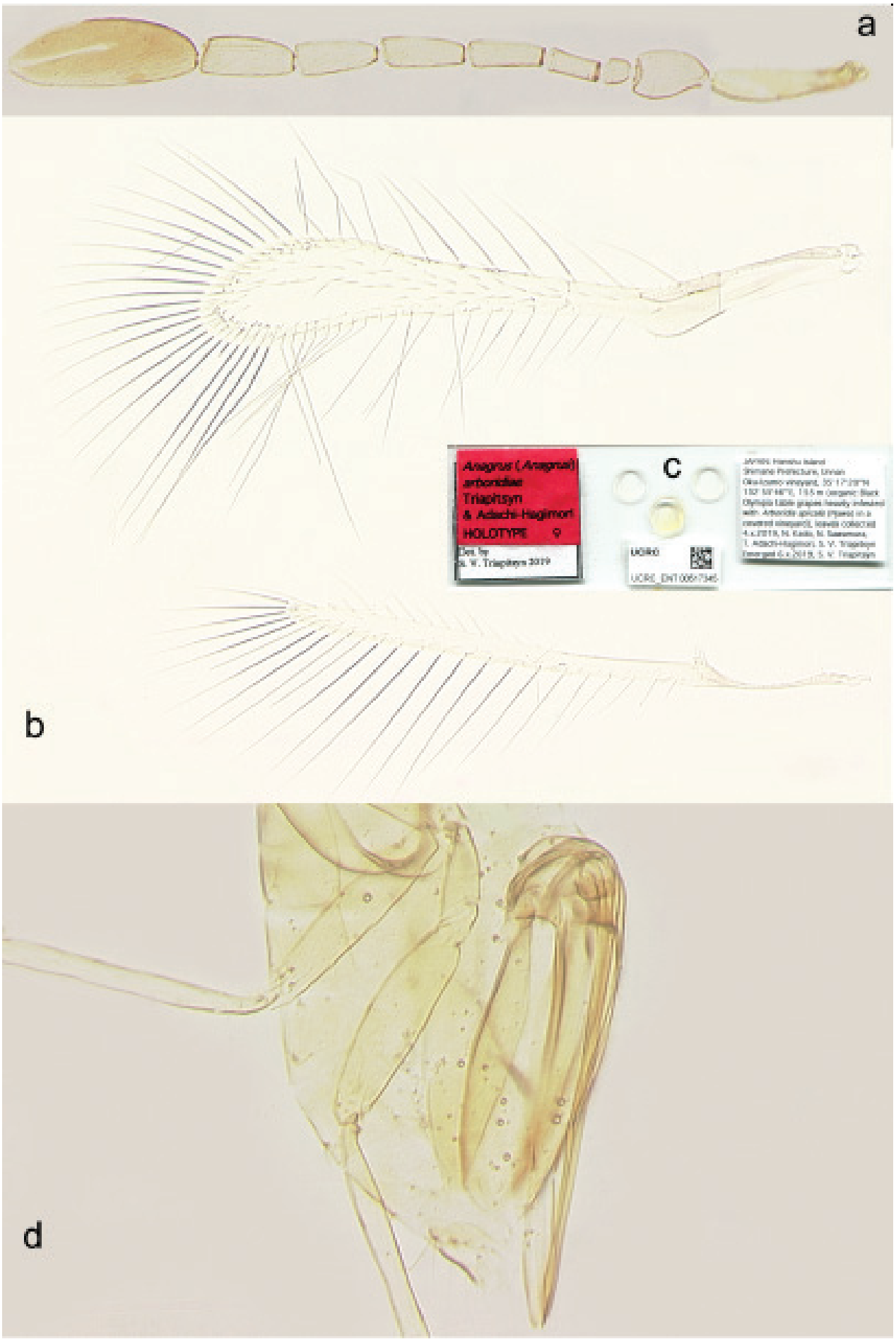

Figure 3. Anagrus arboridiae sp. nov. female (holotype) $\mathbf{a}$ antenna $\mathbf{b}$ fore and hind wings $\mathbf{c}$ slide $\mathbf{d}$ gaster. 
stemmaticum dark brown, clava and two basal gastral terga brown; wings almost hyaline (slightly infumate). Antenna (Fig. 3a) with scape 3.4-4.1× as long as wide, with cross-ridges, 2.0-2.3× length of pedicel; F1 at most slightly longer than wide, almost half of pedicel length; F2 usually notably shorter than following funicular segments but occasionally approximately as long as F3 or even slightly longer (when F3 lacks mps), F4 usually slightly longer than F5 but occasionally subequal to F5, F6 the longest funicular segment; mps on F3 (usually one but often none), F4 (one or two); F5 (one), and F6 (two); clava with three rather short mps (just a little longer than half length of clava), 2.7-3.3x as long as wide, usually slightly longer (but occasionally approximately as long as) than combined length of F5 and F6. Midlobe of mesoscutum without adnotaular setae. Fore wing (Fig. 3b) $6.1-7.0 \times$ as long as wide, longest marginal seta 2.5-2.6x maximum wing width; distal macrochaeta ca. $4 \times$ length of proximal macrochaeta; disc with several rows of setae in addition to admarginal rows of setae (single complete row originating behind apex of venation and two or three irregular rows in the broadest part of disc), leaving a distinct subapical bare area at posterior margin. Hind wing (Fig. 3b) 21-25x as long as wide, longest marginal seta 7.4-9.0× maximum wing width; disc mostly bare except for an almost complete row of microtrichia along posterior margin and 1-3 additional microtrichia at apex. Ovipositor (Fig. 3d) extending anteriorly almost to mesophragma in slide-mounted specimens and at most barely exserted beyond apex of gaster posteriorly (by at most $0.06 \times$ total ovipositor length). Second valvifers (= external plates of ovipositor), e.g., Chiappini et al. (1996), each with 1 seta. Ovipositor 1.9-2.1× length of protibia (2.05x in the holotype).

Measurements $(\mu \mathrm{m})$ of the holotype (as length or length: width). Body: 545; mesosoma 197; gaster 251; ovipositor 212. Antenna: scape 75; pedicel 38; F1 13; F2 27; F3 39; F4 43; F5 42; F6 48; clava 100. Fore wing 463: 74; longest marginal seta 185. Hind wing 424: 20; longest marginal seta 148.

Male (paratypes). Body length of dry-mounted, critical point-dried paratypes $330-460 \mu \mathrm{m}$, and of the slide-mounted paratypes 400-520 $\mu \mathrm{m}$. Body color mainly as in female except most of mesoscutum brown and most of gaster dark brown (light brown basally) (Fig. 2b); flagellum light brown. Antenna (Fig. 4a) with scape 2.6-3.2x as long as wide, F1 usually at least slightly shorter than following flagellomeres but occasionally either much shorter than F2 or approximately as long as F2. Fore wing (Fig. 4b) 5.9-6.4x as long as wide. Genitalia (Fig. 4c) length 86-90 $\mu \mathrm{m}$; digiti hooked.

Etymology. This new species is named after the host leafhopper genus.

Distribution. Palaearctic region: Japan (Honshu and Kyushu Islands).

Host. Cicadellidae: Arboridia (Arboridia) apicalis (Nawa). Only A. apicalis was present on the grapevines both in Aya, Miyazaki Prefecture and in Unnan, Shimane Prefecture, with any other leafhoppers being absent, so this host association of $A$. arboridiae is obvious.

Biology. In the dissected parasitized eggs of $A$. apicalis in the organic vineyard in Unnan, Shimane Prefecture, $A$. arboridiae was observed to develop as a solitary endoparasitoid. Other aspects of its biology are unknown and thus would require further investigations. 


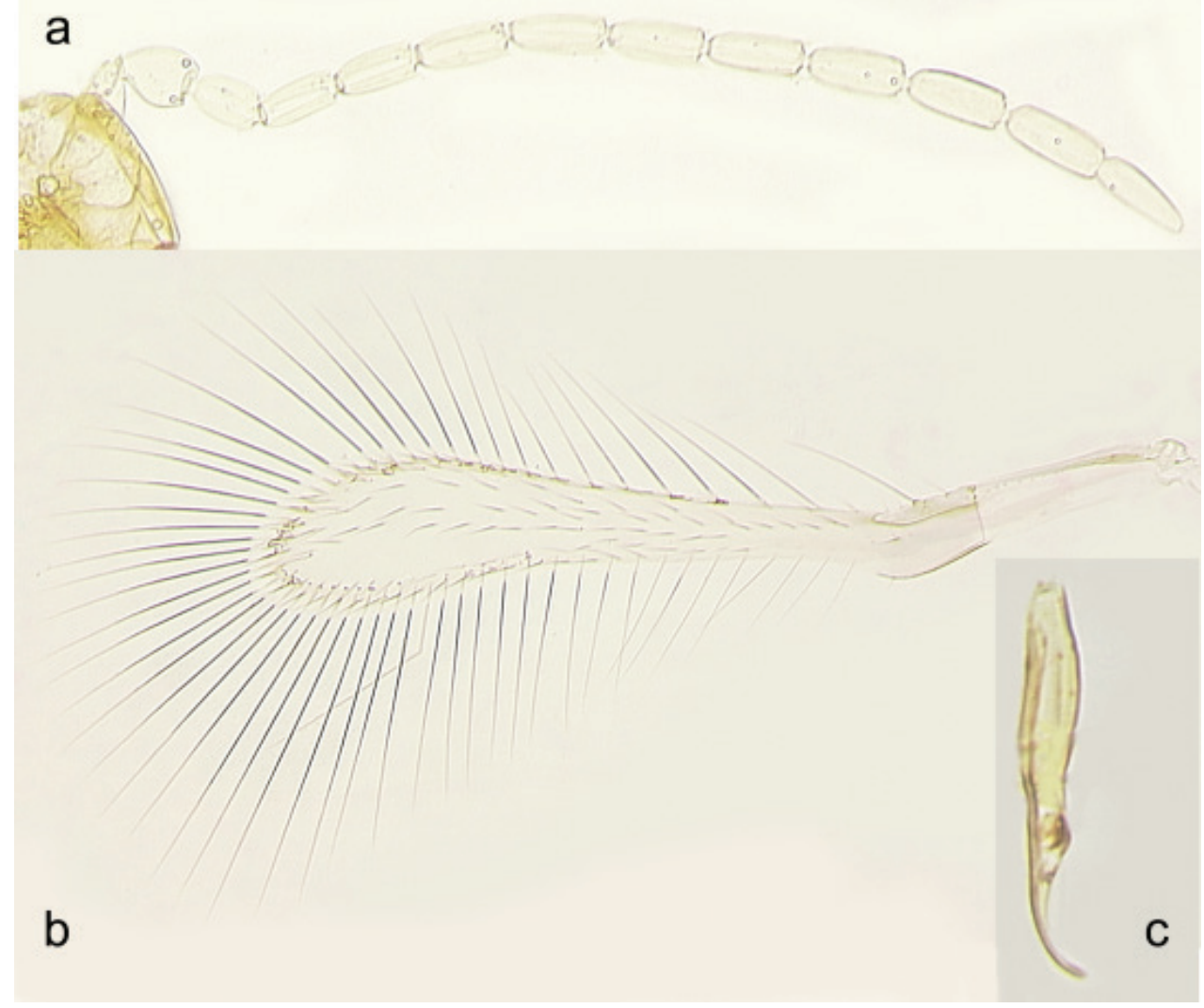

Figure 4. Anagrus arboridiae sp. nov. male (paratypes from Unnan, Shimane Prefecture, Honshu Island, Japan) $\mathbf{a}$ antenna $\mathbf{b}$ fore wing $\mathbf{c}$ genitalia (lateral view).

Remarks. The following species of Anagrus are newly recorded for the fauna of Japan.

Anagrus (Anagrus) flaviapex: Japan, Ryukyu Islands, Okinawa Prefecture, Okinawa Island, Itoman, Makabe, Okinawa Prefectural Agricultural Research Center $\left(26^{\circ} 06^{\prime} 37.9^{\prime \prime} \mathrm{N}, 129^{\circ} 41^{\prime} 16.1^{\prime \prime E}, 52 \mathrm{~m}\right)$, okra (organic experimental plot), 1518.x.2019, S.V. Triapitsyn, T. Adachi-Hagimori, T. Uesato, Malaise trap [1 9 , UCRC; P. F. Rugman-Jones' molecular voucher PR19-505, UCRC_ENT 005517351]. This species has an Oriental and Eastern Palaearctic distribution but is known from different leafhopper and possibly also planthopper hosts (Chiappini and Lin 1998; Triapitsyn 1999, 2015).

The following dry-mounted specimens of Anagrus were found in T. Tachikawa's collection during the first author's visit of ELKU in October 2019 and consequently borrowed, some of them slide-mounted, and then identified. They represent new and interesting host associations for the respective taxa:

Anagrus (Anagrus) atomus (L.): Japan, Shikoku Island, Ehime Prefecture, Kihoku, 24.iii.1966, emerged 28.iii.1966 from eggs of Eurhadina ?betularia Anufriev (a tentative identification of the host per the original label in Japanese) [ 4 q $ᄋ$, ELKU]; 
Anagrus (Anagrus) avalae Soyka: Japan, Honshu Island, Aomori Prefecture, Hirosaki City, vi.1964, R. Tsugawa, from eggs of Edwardsiana ishidae (Matsumura)

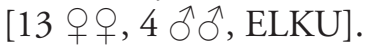

Key to females of the Japanese species of Anagrus

Ocelli on a stemmaticum 3 F2 approximately $1.5 \times \mathrm{F} 1$ length

Anagrus (Anagrella) brevis Chiappini \& Lin F2 at least $4.0 \times$ F1 length Anagrus (Anagrella) birashimai Sahad Frenum with triangular paramedial plates widely separated from each other; metafemur short, less than $2 \times$ trochanter length, trochantellus incision almost half-way between coxa-trochanter and femur-tibia articulations (Anagrus (Paranagrus) Perkins)

Frenum with triangular paramedial plates very close to each other; metafemur long, more than $2 \times$ trochanter length, trochantellus incision ca. one-third way between coxa-trochanter and femur-tibia articulations (Anagrus (Anagrus) Haliday [sensu sricto]).

Ovipositor projecting beyond apex of gaster by approximately $1 / 3$ of its total length; ovipositor length: protibia length ratio at least 3.5

Anagrus (Paranagrus) perforator (Perkins) Ovipositor not projecting or at most slightly projecting beyond apex of gaster; ovipositor length: protibia length ratio at most 2.5

Anagrus (Paranagrus) optabilis (Perkins)

Clava with 3 mps (atomus species group)

Clava with 5 mps (incarnatus species group)

Fore wing length: width ratio more than 10

Anagrus (Anagrus) frequens Perkins

Fore wing length: width ratio less than 10 .

Body light brown or brown (at most frenum, propodeum and apex of gaster yellow)

Body pale yellow, yellow, or greyish yellow (at most parts of mesoscutum and 2 basal gastral terga light brown or brown)

F3 without mps; gaster uniformly colored... Anagrus (Anagrus) atomus (L.) F3 with 1 mps; 2 apical gastral terga contrastingly yellow .....

Anagrus (Anagrus) flaviapex Chiappini \& Lin Body pale yellow except mesoscutum mostly light brown and 2 basal gastral terga contrastingly brown

...Anagrus (Anagrus) arboridiae Triapitsyn \& Adachi-Hagimori, sp. nov. Body yellow or greyish yellow, with 2 basal gastral terga concolorous with the rest of metasoma. Anagrus (Anagrus) japonicus Sahad Midlobe of mesoscutum with adnotaular setae. 11

Midlobe of mesoscutum without adnotaular setae 
11 Body light yellow except mesoscutum partially a little darker; each external plate of ovipositor (second valvifer) with 2 setae

Anagrus (Anagrus) avalae Soyka

- $\quad$ Body brown; each external plate of ovipositor with 3 setae.

Anagrus (Anagrus) subfuscus Foerster

12 Fore wing approximately $6.3 \times$ as long as wide

Anagrus (Anagrus) takeyanus Gordh

- $\quad$ Fore wing at least $7.0 \times$ as long as wide 13

13 F2 the longest funicular segment ... Anagrus (Anagrus) incarnatus Haliday F2 at least slightly shorter than following funicular segments.

Anagrus (Anagrus) rugmanjonesi Triapitsyn \& Adachi-Hagimori

\section{Trichogrammatidae}

\section{Oligosita pallida Kryger, 1919}

Figure 5

Oligosita pallida Kryger, 1919:318-319. 2 syntype 우우 [Zoological Museum, Natural History Museum of Denmark, University of Copenhagen, Copenhagen, Denmark (ZMUC)] (not examined). Type locality: Gentofte, Denmark.

Oligosita pallida Kryger: Viggiani 1987: 543-546 (synonymy, type material, diagnosis, distribution, host associations, illustrations); Liu and Li 2019: 1125 (key), 1126-1127 (taxonomic history, list of synonyms, distribution, hosts).

Oligosita sp.: Triapitsyn, 1998: 83 (reared from eggs of an Arboridia sp. in Turkmenistan).

Material examined. Japan, Honshu Island, Shimane Prefecture: Izumo, Taisha (emerged from leaves of non-organic table grape infested with $A$. apicalis in a covered vineyard): $35^{\circ} 21^{\prime} 11^{\prime \prime N}, 132^{\circ} 40^{\prime} 59^{\prime \prime E}, 8$ m, Shine Muscat grapes: collected 25.ix.2019, N. Kado, N. Sawamura, emerged 2-6.x.2019, S. V. Triapitsyn, N. Kado [2 ô ô, UCRC]; collected 30.ix.2019, N. Kado, N. Sawamura, emerged 6.x.2019, S. V. Triapitsyn [1 9 , UCRC]; collected 2.x.2019, N. Kado, Y. Narai, T. Adachi-Hagimori, S. V. Triapitsyn, emerged 3-5.x.2019, S. V. Triapitsyn, N. Kado [3 qq, UCRC]. 35²1'21"N, 132²1'22"E, 3 m, Watanabe vineyard, Delaware grapes, collected 1.x.2019, N. Kado, N. Sawamura:

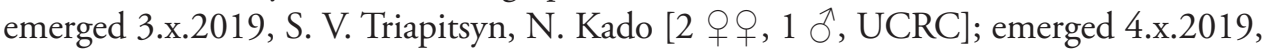
S. V. Triapitsyn, N. Kado [1 ㅇ, UCRC]. Unnan, Oku-Izumo vineyard, 35 $17^{\prime} 20^{\prime \prime N}$, $132^{\circ} 55^{\prime} 46 " \mathrm{E}, 155 \mathrm{~m}$ (organic Black Olympia table grapes heavily infested with $A$. apicalis in a covered vineyard), leaves collected 4.x.2019, N. Kado, N. Sawamura, T. Adachi-Hagimori, S. V. Triapitsyn, emerged 17.x.2019, N. Kado [1 क, UCRC].

Other material examined. France, Gironde, Sainte Colombe, M. van Helden,

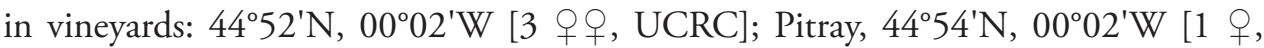
UCRC]. Iran: Isfahan, vi.2000, S. Hesami, from grape leafhopper [1 9, UCRC]. Khorasan, Fazd Village, 10.x.1994, J. Vafabaksh, from grape leaves [1 + , UCRC]. 


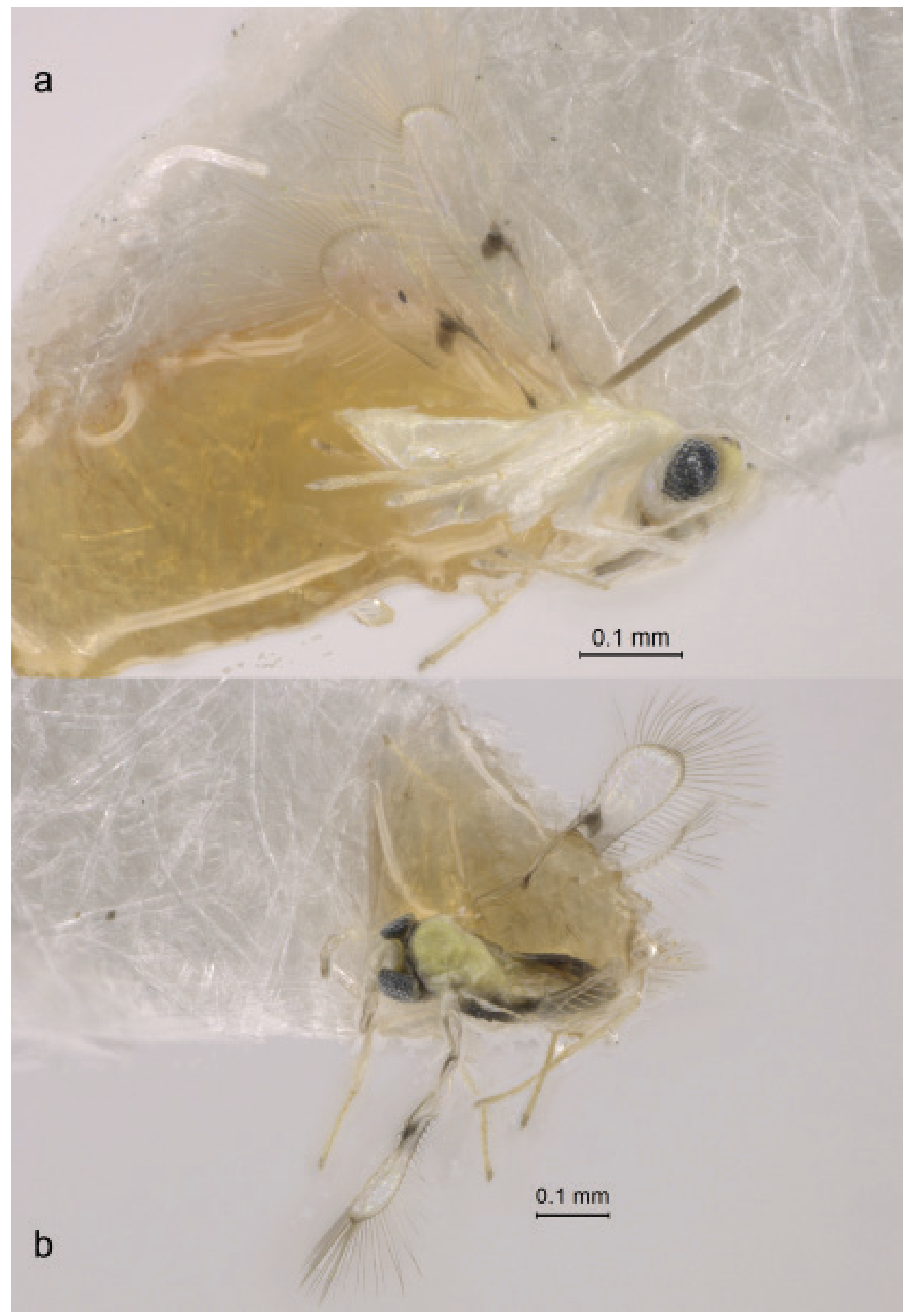

Figure 5. Oligosita pallida (Taisha, Izumo, Shimane Prefecture, Honshu Island, Japan) a habitus of female (lateral view) b habitus of male (dorsolateral view). 
Turkmenistan, Ashgabat, 24.viii.1993, S. N. Myartseva, from eggs of Arboridia (Arboridia) hussaini (Ghauri) on grape [1 $q$, UCRC].

Distribution. Palaearctic region: China (Liu and Li 2019), Croatia (Bakkendorf 1971 [for Oligosita tominici Bakkendorf, a synonym of O. pallida (Viggiani 1987)]), Czech Republic, Denmark, Hungary, Iran, Italy, Netherlands, Turkey, UK (Noyes 2019), France, Japan, and Turkmenistan (new records).

Hosts. Cicadellidae: Arboridia (Arboridia) apicalis (Nawa), A. (Arboridia) hussaini (Ghauri) (Triapitsyn 1998 [as Arboridia sp. for Oligosita sp.]) (new records), as well as A. (Arboridia) adanae (Dlabola) (Viggiani 1987; Yiğit and Erkiliç 1987), $A$. ( $A r$ boridia) kermanshah Dlabola (Mostaan and Akbarzadeh 1995), Edwardsiana rosae (L.) (Viggiani 1987), Zygina (Zygina) eburnea Fieber (Bakkendorf 1971 [as Erythroneura eburnea for O. tominici]), and Zygina (Zygina) rhamni Ferrari (Viggiani 1987).

Remarks. Females of this distinctive species can be recognized by the uniformly pale color of the body (Fig. 5a), while in males the sides of metasoma and sometimes mesosoma are dark (Fig. 5b). Other distinguishing features of both sexes include a rather long clava of the antenna and a characteristic fore wing with a distinctive dark spot behind the apex of venation (Fig. 5), as described and illustrated by Kryger (1919) and Viggiani (1987).

Other examined female specimens of an Oligosita sp. in UCRC, collected from grape leaves in Iran, have several small dark spots on the sides of metasoma; thus, we cannot positively identify them as $O$. pallida without availability of a thorough assessment of intraspecific variation of body color in this species.

\section{Oligosita sp.}

Figure 6a

Material examined. Japan, Honshu Island, Shimane Prefecture, Izumo, Taisha, $35^{\circ} 21^{\prime} 21 " \mathrm{~N}, 132^{\circ} 41^{\prime} 22^{\prime \prime E}, 3$ m, 5.x.2019, N. Kado, N. Sawamura, T. Adachi-Hagimori, S. V. Triapitsyn (sweeping upon leaves of non-organic Delaware table grapes infested with $A$. apicalis in a covered Watanabe vineyard) [1 9 , UCRC].

Distribution. Palaearctic region: Japan (Honshu Island).

Host. Cicadellidae: Arboridia (Arboridia) apicalis (Nawa). This tentative host association will need to be confirmed by experimental work using sentinel eggs of this leafhopper.

Remarks. Because taxonomy of the genus Oligosita Walker is in flux and no working keys are available, we could not positively identify this specimen to the species. Its body color is more or less light brown except dorsum of mesosoma is mostly yellow (Fig. 6a).

\section{Aphelinoidea (Aphelinoidea) sp.}

Figure $6 \mathrm{~b}$

Material examined. Japan, Honshu Island, Shimane Prefecture, Unnan, Oku-Izumo vineyard, $35^{\circ} 17^{\prime} 20^{\prime \prime} \mathrm{N}, 132^{\circ} 55^{\prime} 46^{\prime} \mathrm{E}, 155 \mathrm{~m}$, leaves of organic Black Olympia table 


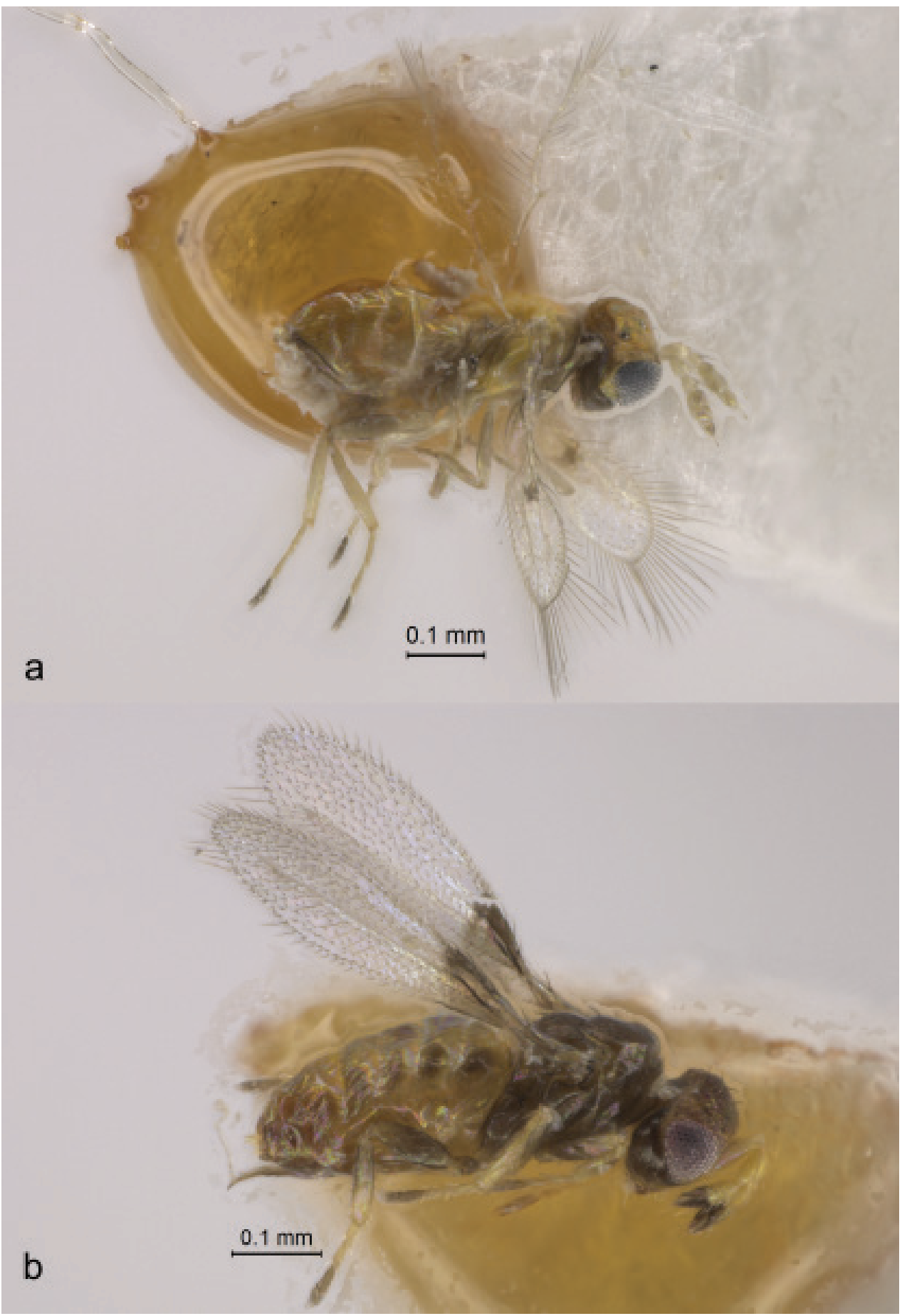

Figure 6. Habitus in lateral view a Oligosita sp. female (Taisha, Izumo, Shimane Prefecture, Honshu Island, Japan) b Aphelinoidea (Aphelinoidea) sp. male (Unnan, Shimane Prefecture, Honshu Island, Japan). 
grapes heavily infested with $A$. apicalis in a covered vineyard collected 4.x.2019, N. Kado, N. Sawamura, T. Adachi-Hagimori, S. V. Triapitsyn, emerged 5.x.2019, S. V. Triapitsyn [1 $\overbrace{}^{\lambda}, \mathrm{UCRC}$.

Distribution. Nearctic region: USA (Nebraska); Palaearctic region: Japan (Honshu Island).

Host. Cicadellidae: Arboridia (Arboridia) apicalis (Nawa). This tentative host association will need to be confirmed by experimental work using sentinel eggs of this leafhopper.

Remarks. This specimen is similar to Aphelinoidea (Aphelinoidea) waterhousei (Blood $\&$ Kryger) which belongs to the semifuscipennis species group of the nominate subgenus of the genus Aphelinoidea Girault, formerly placed in the synonymized subgenus Aphelinoidea (Diaclava Blood \& Kryger) (Triapitsyn 2018). Like A. waterhousei from England, UK, known from the single male specimen, the one from Japan (Fig. 6b) has apical segment of the clava contrastingly darker than the light-colored basal segment, and the marginal vein of its fore wing is notably thickened while the stigmal vein is short, inconspicuous. But because the fore wing of the specimen from Japan is notably wider and its marginal setae are relatively shorter (ca. one-third of the greatest fore wing width), it is unlikely to be $A$. waterhousei; rather, it is more similar to the unidentified male specimen from Nebraska, USA which has the same features, as illustrated by Triapitsyn (2018: 78, figs 93-97).

\section{Molecular analyses}

Sequences of the COI gene provided strong evidence that $A$. arboridiae is distinct from $A$. flaviapex and also from members of the $A$. atomus species complex for which comparative sequence data are available. The two $A$. arboridiae specimens (both from Unnan, Shimane Prefecture, Honshu Island) shared a single haplotype which, based on uncorrected p-distance, differed from the nearest taxon, A. japonicus, by 5\%, and from $A$. flaviapex by $7.3 \%$ (Fig. 7; Table 1). In turn, these three species were at least $6.4 \%$ divergent from previously sequenced members of the $A$. atomus species complex, which in the Palaearctic region includes A. atomus, A. (Anagrus) lindberginae Nugnes \& Viggiani, A. (Anagrus) nepetellae Viggiani \& Nugnes, and A. (Anagrus) parvus Soyka (Fig. 7; Table 1). Intraspecific variation in the cloned ITS2 sequences was minimal and largely restricted to the length of microsatellite repeat regions. In contrast, the five

Table I. Genetic divergence between Anagrus arboridiae sp. nov., A. japonicus, A. flaviapex, and other members of the $A$. atomus species group including those in the $A$. atomus species complex ${ }^{*}$, based on DNA sequences of the mitochondrial COI gene. Diagonal element shows intraspecific variation (only when more than one sequence was considered). Average pairwise uncorrected p-distances calculated using MEGA 6.06.

\begin{tabular}{lcccc}
\hline & A. arboridiae & A. japonicus & A. flaviapex & ${\text { A. } \text { atomus }^{*}}^{\text {A. }_{\text {incarnatus }}{ }^{\text {a }}}$ \\
\hline A. arboridiae & 0.000 & & & \\
A. japonicus & 0.050 & 0.005 & - & \\
A. flaviapex & 0.073 & 0.074 & 0.064 & 0.034 \\
A. atomus $^{*}$ & 0.073 & 0.071 & 0.082 & 0.080 \\
A. incarnatus $^{\S}$ & 0.073 & 0.078 & - \\
\hline
\end{tabular}

*Anagrus atomus species complex as considered by Zanolli et al. (2016) and Nugnes et al. (2017); ${ }^{\S}$ outgroup 


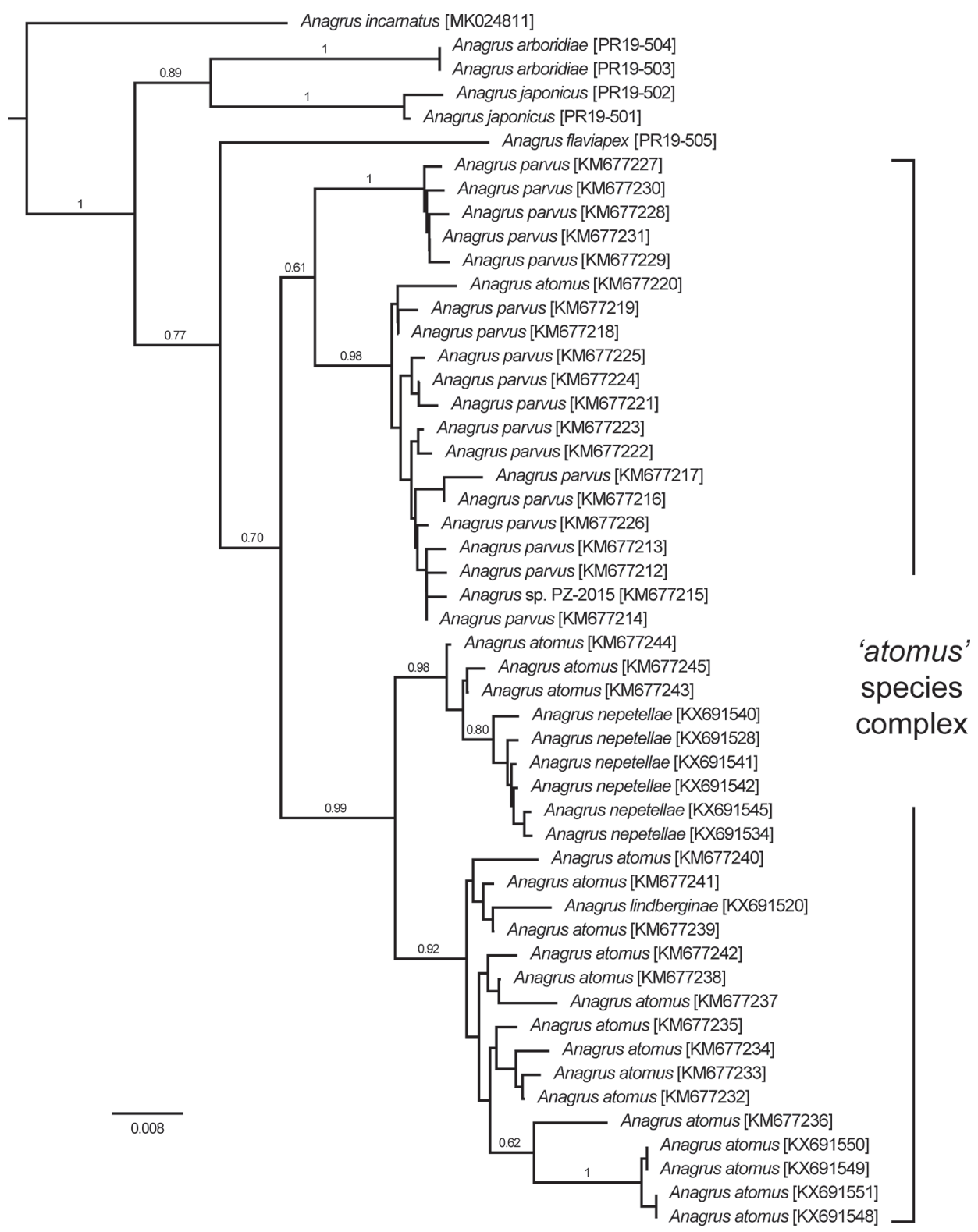

Figure 7. Relationship of Anagrus arboridiae sp. nov. with other members of the $A$. atomus species group for which reliable DNA sequences are available, based on a $587 \mathrm{bp}$ fragment of COI. Optimal NJ tree with the sum of branch length $=0.34117946$. The percentage of replicate trees in which the associated taxa clustered together in the bootstrap test (1000 replicates) are shown next to the branches and the tree is drawn to scale, with branch lengths indicating uncorrected p-distance. Analyses conducted in MEGA 6.06.

specimens in this study showed clear interspecific differences between $A$. arboridiae, $A$. flaviapex, and $A$. japonicus in both length $(-517,-591$ and $-534 \mathrm{bp}$, respectively) and nucleotide constitution (see GenBank accessions MT414958-MT414966). 


\section{Discussion}

The results of this study are well within the expected composition of the genera of the parasitoids, as outside of Japan members of both Anagrus and Oligosita are known to parasitize eggs of other species of Arboridia; however, at species level the parasitoids turned out to be mostly different. Besides the above-mentioned A. turpanicus (parasitizing eggs of the invasive $A$. kakogawana in Xinjiang, China), which unlike $A$. arboridiae belongs to the incarnatus species group of the nominate subgenus of Anagrus (Hu and Triapitsyn 2016), A. (Anagrus) atomus (L.) from the atomus species group of the same subgenus had been recorded in Khorasan Province of Iran from eggs of Arboridia kermanshah, along with an Oligosita sp. (Triapitsyn 1998), and later was studied by Hesami et al. (2004, 2009). Indeed, Oligosita pallida had been previously reported as a very effective natural enemy of the same host leafhopper in the Iranian province of West Azerbaijan in the absence of insecticide treatments (Mostaan and Akbarzadeh 1995). Both $A$. atomus and $O$. pallida were also recorded as egg parasitoids of $A$. (Arboridia) adanae in Turkey (Viggiani 1987; Yiğit and Erkiliç 1987). An Oligosita sp. was identified in Turkmenistan from eggs of Arboridia sp. on grape (Triapitsyn 1998); it is shown here to belong to $O$. pallida parasitizing eggs of $A$. (Arboridia) hussaini. Because taxonomy of the speciose and very difficult genus Oligosita is in flux worldwide, few previous species identifications can be trusted beyond the generic ones and thus most, especially those outside of Europe, need confirmation.

Of note is the fact that in Japan, most of the obtained Oligosita spp. from Shimane Prefecture emerged from table grape leaves collected in non-organic vineyards where no $A$. arboridiae were present, whereas in the organic vineyard in the same prefecture $A$. arboridiae was abundant while only one specimen of $O$. pallida was collected. That perhaps could be due to the longer developmental times of Oligosita spp. versus Anagrus spp. and the fact that the former spin a cocoon at pupal stage and the latter do not (Chiappini 2002), thus presumably making the immature stages of these trichogrammatids more resistant to insecticides. That assumption, however, needs to be further investigated by a thorough experimental work.

These results could be of importance for other agricultural crops as well because A. apicalis is also known to feed on very common, aforementioned fruit trees in Japan. Furthermore, knowledge of the egg parasitoids of Arboridia spp. in Japan would be important for the potential classical biological control programs against $A$. kakogawana in other countries of Asia and Europe within the Palaearctic region, where it has established recently as an invasive pest of grapes (Chireceanu et al. 2019).

\section{Acknowledgments}

We thank Dmitry A. Dmitriev (INHS) for identification of the grape leafhoppers, Vladimir V. Berezovskiy (UCRC) for mounting specimens, as well as grape growers in Shimane Pre- 
fecture and Yoshitada Katsuki (Katsuki Wines LLC, Kitamata, Aya, Miyazaki Prefecture) for allowing us to collect specimens at their properties. We are also grateful to Toshiharu Mita (ELKU) for the loan of specimens to SVT and Takumi Uesato (Okinawa Prefectural Agricultural Research Center, Makabe, Itoman, Okinawa, Japan) who kindly helped with collecting by a Malaise trap on Okinawa Island. SVT's visit to Japan in October-November 2019 was sponsored by the Short-term Invitational Fellowship for Research in Japan from the Japan Society for the Promotion of Science ( $2^{\text {nd }}$ Recruitment for 2019).

\section{References}

Adachi-Hagimori T, Triapitsyn SV, Uesato T (unpublished) Egg parasitoids (Hymenoptera: Mymaridae) of Amrasca biguttula (Ishida) (Hemiptera: Cicadellidae) from Okinawa Island, a pest of okra in Japan. Journal of Asia-Pacific Entomology (submitted, in review).

Arai T, Toyama M (2018) Occurrence of Arboridia apicalis (Nawa) (Hemiptera: Cicadellidae) under reduced insecticide management and reflective sheet mulching in grapevine cultivar 'Shine Muscat'. Bulletin of the NARO, Fruit Tree and Tea Science 2: 33-41. [In Japanese] Bakkendorf O (1971) Description of Oligosita tominici n. sp. [Hym., Trichogrammatidae] and notes of Anagrus atomus (L.) and Anaphes autumnalis Foerster [Hym. Mymaridae]. Entomophaga 16(4): 363-366. https://doi.org/10.1007/BF02370918

Benson DA, Karsch-Mizrachi I, Lipman DJ, Ostell J, Wheeler DL (2008) GenBank. Nucleic Acids Research 36: D25-D30. https://doi.org/10.1093/nar/gkm929

Chiappini E (2002) Anagrus and Oligosita: different strategies adopted to develop in the same host egg (Hymenoptera: Mymaridae, Trichogrammatidae). In: Melika G, Thuróczy C (Eds) Parasitic Wasps: Evolution, Systematics, Biodiversity and Biological Control. International Symposium: "Parasitic Hymenoptera: taxonomy and biological control" (14-17 May 2001, Köszeg, Hungary). Agroinform Kiadó és Nyomda Kft., Budapest, 261-266.

Chiappini E, Lin N-q (1998) Anagrus (Hymenoptera: Mymaridae) of China, with descriptions of nine new species. Annals of the Entomological Society of America 91(5): 549-571. https://doi.org/10.1093/aesa/91.5.549

Chiappini E, Mazzoni E (2000) Differing morphology and ultrastructure of the male copulatory apparatus in species-groups of Anagrus Haliday (Hymenoptera: Mymaridae). Journal of Natural History 34(8): 1661-1676. https://doi.org/10.1080/00222930050117549

Chiappini E, Triapitsyn SV, Donev A (1996) Key to the Holarctic species of Anagrus Haliday (Hymenoptera: Mymaridae) with a review of the Nearctic and Palaearctic (other than European) species and descriptions of new taxa. Journal of Natural History 30: 551-595. https://doi.org/10.1080/00222939600770301

Chireceanu C, Nedelcea D, Seljak G (2019) First record of the Japanese grape leafhopper Arboridia kakogawana (Matsumura, 1932) (Hemiptera: Cicadellidae) from Romania. Bulletin OEPP/EPPO Bulletin 49(2): 391-397. https://doi.org/10.1111/epp.12585

Dmitriev DA (2019) 31 Interactive keys and taxonomic databases. https:/doi. org/10.1155/2019/8750643 [last accessed 6 November 2019] 
Dworakowska I (1970) On the genus Arboridia Zachv. (Auchenorrhyncha, Cicadellidae, Typhlocybinae). Bulletin de l'Académie Polonaise des Sciences, Série des Sciences Biologiques 18(10): 607-615.

Gibson GAP (1997) Chapter 2. Morphology and terminology. In: Gibson GAP, Huber JT, Woolley JB (Eds) Annotated Keys to the Genera of Nearctic Chalcidoidea (Hymenoptera). NRC Research Press, Ottawa, 16-44.

Guglielmino A, Xu Z, Bückle C, Dong W (2012) Description of a new species of Arboridia (Hemiptera: Auchenorrhyncha: Cicadellidae: Typhlocybinae) from China. Florida Entomologist 95(4): 877-881. https://doi.org/10.1653/024.095.0409

Hesami S, Seyedoleslami H, Ebadi R (2004) Biology of Anagrus atomus (Hym., Mymaridae), an egg parasitoid of the grape leafhopper Arboridia kermanshah (Hom., Cicadellidae). Entomological Science 7: 271-276. https://doi.org/10.1111/j.1479-8298.2004.00073.x

Hesami S, Seyedoleslami H, Hatami B (2009) Impact of overwintering refugia of Anagrus atomus on egg parasitism of grape leafhopper, Arboridia kermanshah. Plant Protection Journal, Islamic Azad University, Shiraz Branch 1(1): 94-106.

Hu H-y, Triapitsyn SV (2016) Anagrus turpanicus sp. n. (Hymenoptera: Mymaridae) from China, an egg parasitoid of Arboridia kakogawana [sic] (Hemiptera: Cicadellidae). Zootaxa 4161(4): 573-578. https://doi.org/10.11646/zootaxa.4161.4.9

Katoh K, Standley DM (2013) MAFFT multiple sequence alignment software version 7: improvements in performance and usability. Molecular Biology and Evolution 30: 772-780. https://doi.org/10.1093/molbev/mst010

Kryger JP (1919 [1918]) The European Trichogramminae. Entomologiske Meddelelser 12(2): 257-354.

Li Q, Hu H, Triapitsyn SV, Yi L, Lu J (2018) Anagrus dmitrievi sp. n. (Hymenoptera, Mymaridae), an egg parasitoid of Zyginidia eremita (Hemiptera, Cicadellidae), a pest of maize in Xinjiang, China. ZooKeys 736: 43-57. https://doi.org/10.3897/zookeys.736.20883

Liu S, Li C (2019) A new species, first report of a male and new distributional records for five species of Oligosita Walker (Hymenoptera: Trichogrammatidae) from China. Journal of Forestry Research 30(3): 1123-1130. https://doi.org/10.1007/s11676-018-0749-8

Matsumura S (1932) A revision of the Palaearctic and Oriental Typhlocybid-genera with descriptions of new species and new genera. Insecta Matsumurana 6(3): 93-120.

Mostaan M, Akbarzadeh G (1995) Studies on the egg parasitoid of the Grapevine leafhopper (Arboridia kermanshah Dlab.). In: Wajnberg E (Ed.) Trichogramma and Other Egg Parasitoids: Proceedings of the $4^{\text {th }}$ International Symposium held in Cairo (Egypt), October 4-7, 1994. INRA Ed., Paris (Les Colloques, n73), 201-202.

Noyes JS (2019) Universal Chalcidoidea database. World Wide Web electronic publication, the Natural History Museum, London. http://www.nhm.ac.uk/chalcidoids [last accessed 11 November 2019]

Nugnes F, Bernardo U, Viggiani G (2017) An integrative approach to species discrimination in the Anagrus atomus group sensu stricto (Hymenoptera: Mymaridae), with a description of a new species. Systematics and Biodiversity 15(6): 582-599. https://doi.org/10.1080/1 4772000.2017.1299811 
Oh S, Choe K-R, Jung S (2015) Two new species of the genus Arboridia Zachvatkin (Hemiptera: Auchenorrhyncha: Cicadellidae: Typhlocybinae) from Korea. Zootaxa 3918(3): 446-450. https://doi.org/10.11646/zootaxa.3918.3.9

Sakagami Y (2003) Grape [plate]. In: Sakagami Y, Kudo A (Eds) A handbook of diseases and insect pests of fruit trees (Vol. 2). Pears, grape, persimmon, chestnut and fig (Revised Edition). Japan Plant Protection Association, Komagome-1-chome, Toshima-ku, Tokyo, 103 pp. [In Japanese]

Song Y-H, Li Z-Z (2013) Some new species and new record of the genus Arboridia Zachvatkin (Hemiptera: Cicadellidae: Typhlocybinae) from six provinces of China. Zootaxa 3613(3): 229-244. https://doi.org/10.11646/zootaxa.3613.3.2

Song Y-H, Li Z-Z (2015) Review of the genus Arboridia Zachvatkin (Hemiptera: Cicadellidae: Typhlocybinae), with description of two new species from China. Zootaxa 3990(4): 584-592. https://doi.org/10.11646/zootaxa.3990.4.7

Tamura K, Stecher G, Peterson D, Filipski A, Kumar S (2013) MEGA6: Molecular Evolutionary Genetics Analysis version 6.0. Molecular Biology and Evolution 30: 2725-2729. https://doi.org/10.1093/molbev/mst197

Tanaka F, Kondo A, Henmi T (1986) Catches of the grape leafhopper, Arboridia apicalis Nawa (Homoptera: Cicadellidae), on yellow cylindrical sticky trap. Japanese Journal of Applied Entomology and Zoology 30(4): 305-307. [In Japanese] https://doi.org/10.1303/ jjaez.30.305

Triapitsyn SV (1998) Anagrus (Hymenoptera: Mymaridae) egg parasitoids of Erythroneura spp. and other leafhoppers (Homoptera: Cicadellidae) in North American vineyards and orchards: a taxonomic review. Transactions of the American Entomological Society 124(2): 77-112.

Triapitsyn SV (1999) Description of the male of Anagrus flaviapex (Hymenoptera: Mymaridae), with new distribution and host records. Entomological News 110(4): 237-239.

Triapitsyn SV (2015) Taxonomy of the genus Anagrus Haliday (Hymenoptera: Mymaridae) of the world: an annotated key to the described species, discussion of the remaining problems, and a checklist. Acta Zoológica Lilloana 59: 3-50.

Triapitsyn SV (2018) Review of the Palearctic Aphelinoidea (Hymenoptera: Trichogrammatidae), with focus on the species described by Ś. Nowicki. Israel Journal of Entomology 48(2): 33-81.

Triapitsyn SV, Adachi-Hagimori T, Rugman-Jones PF, Barry A, Abe A, Matsuo K, Ohno K (2019[a]) Egg parasitoids of the tea green leafhopper Empoasca onukii (Hemiptera, Cicadellidae) in Japan, with description of a new species of Anagrus (Hymenoptera, Mymaridae). ZooKeys 836: 93-112. https://doi.org/10.3897/zookeys.836.32634

Triapitsyn SV, Rugman-Jones PF, Tretiakov PS, Luft Albarracin E, Moya-Raygoza G, Querino RB (2019[b]) Molecular, morphological and biological differentiation between Anagrus virlai sp. n., an egg parasitoid of the corn leafhopper Dalbulus maidis (Hemiptera: Cicadellidae) in the New World, and Anagrus incarnatus from the Palaearctic region (Hymenoptera: Mymaridae). Neotropical Entomology 48(1): 87-97. https://doi.org/10.1007/ s13744-018-0606-7 
Triapitsyn SV, Rugman-Jones PF, Tretiakov PS, Shih H-T, Huang S-H (2018) New synonymies in the Anagrus incarnatus Haliday 'species complex' (Hymenoptera: Mymaridae) including a common parasitoid of economically important planthopper (Hemiptera: Delphacidae) pests of rice in Asia. Journal of Natural History 52(43-44): 2795-2822. https://doi.org/1 0.1080/00222933.2018.1552333

Truett GE, Heeger P, Mynatt RL, Truett AA, Walker JA, Warman ML (2000) Preparation of PCR Quality Mouse Genomic DNA with Hot Sodium Hydroxide and Tris (HotSHOT). BioTechniques 29: 52-54. https://doi.org/10.2144/00291bm09

Viggiani G (1987) Notes on Oligosita pallida Kryger and on other species of the group minima Girault (Hymenoptera: Trichogrammatidae). Redia 70: 543-547.

Yamada K (2003) Grape. In: Sakagami Y, Kudo A (Eds) A Handbook of Diseases and Insect Pests of Fruit Trees (Vol. 2). Pears, Grape, Persimmon, Chestnut and Fig (Revised Edition). Japan Plant Protection Association, Komagome-1-chome, Toshima-ku, Tokyo, 105 pp. [In Japanese]

Yiğit A, Erkiliç L (1987) Studies on egg-parasitoids of grape leafhopper, Arboridia adanae Dlab. (Hom.: Cicadellidae), injurious in Southern Anatolia vineyards. In: Proceedings of the First Turkish National Congress of Entomology (13-16 October 1987, Izmir), 35-42. [In Turkish]

Zanolli P, Martini M, Mazzon L, Pavan F (2016) Morphological and molecular identification of Anagrus 'atomus' group (Hymenoptera: Mymaridae) individuals from different geographic areas and plant hosts in Europe. Journal of Insect Science 16(1): 38, 1-14. https:// doi.org/10.1093/jisesa/iew017 